Acknowledgements: This study was funded by the Logres Trust.

Disclosure of Interest: None declared

DOI: 10.1136/annrheumdis-2018-eular.7164

\section{OP0164-HPR IMPACT OF A NURSE-LED PROGRAM OF PATIENT SELF-ASSESSMENT AND SELF-MANAGEMENT AXIAL SPONDYLOARTHRITIS: RESULTS OF A PROSPECTIVE, MULTICENTRE, RANDOMISED, CONTROLLED TRIAL (COMEDSPA)}

A. Moltó $^{1}$, A. Etchieto ${ }^{1}$, S. Poiraudeau ${ }^{1}$, L. Gossec ${ }^{2}$, P. Claudepierre ${ }^{3}$,

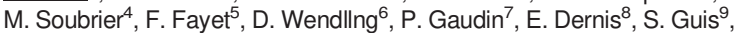
S. Pouplin ${ }^{10}$, A. Ruyssen-Witrand ${ }^{11}$, M. Dougados ${ }^{1}$. ${ }^{1}$ Cochin; ${ }^{2}$ Pitié-Salpêtrière; ${ }^{3}$ Henri Mondor, Paris; ${ }^{4} \mathrm{CHU}$ Clermont-Ferrand, Clermont-Ferrand; ${ }^{5} \mathrm{CHU}$ Clermont-Ferrand, Paris; ${ }^{6} \mathrm{CHU}$ Besançon, Besançon; ${ }^{7} \mathrm{CHU}$ Grenoble, Grenoble; ${ }^{8} \mathrm{CH}$ Le Mans, Le Mans; ${ }^{9} \mathrm{AP}-\mathrm{HM}$, Marseille; ${ }^{10} \mathrm{CHU}$ Rouen, Rouen; ${ }^{11} \mathrm{CHU}$ Toulouse, Toulouse, France

Background: Nurses should promote self-assessment and self-management skills in order that patients might achieve a greater self efficacy and improvement in patients with axSpA.

Objectives: To evaluate the impact of a nurse-led program of self-management/assessment for disease activity program in axSpA.

Methods: Prospective, randomised, controlled, open, 12 month trial (NCT02374749). Participants 1/Patients: consecutive Axial SpA patients (according to rheumatologist) attending a clinic of the participating centres were invited $0.2 /$ Nurses :all participated at a 1 day meeting prior the start of the study. Study treatment: a program including: 1) Self-management=a) a video explaining the disease, the interest of smoking cessation in axial SpA, the role of NSAIDs as cornerstone treatment in axSpA in the absence of contra-indications, the interest of physical activity and exercise, followed by a discussion with the nurse; $b$ ) physical examination by the nurse to check for the presence of spinal deformitiesand depending on the absence/presence of such deformities projection of a specific video of home-based exercises. 2) Self-assessment: Video presentation of the rationale of the use of a composite index (ASDAS/BASDAI), followed by discussion with the nurse. Explanation by the nurse of the collection, calculation of BASDAI and ASDAS Treatment allocation: after written informed consent, the treatment was allocated randomly via en electronic system. Outcome variables: Primary: The level of coping ( $0-10$, where $0=$ very well) after 12 months. Other variables: Successful smoking cessation, NSAID intake, Number of home-based or supervised exercise, international physical activity questionnaire (IPAQ)

Results: Baseline characteristics of the 502 recruited patients (250 and 252 in the active and control groups, respectively): Age: $46.7 \pm 12.2$ years, male gender: $62.7 \%$, disease duration: $13.7 \pm 11.0 \mathrm{y}$, Xray sacroiliitis $62.8 \%$, MRI sacroiliitis $65.7 \%$, current biologic treatment: $78.3 \%$, ASDAS-CRP: $1.9 \pm 0.8$, BASFI: 25.6 \pm 22 .3. After 1 year, coping levels were lower in the active group, but not significant $(2.8 \pm 2.0$ vs $3.0 \pm 2.1, p=0.3)$. However, there was a significant decrease in the BASDAI in the active group (- $1.2 \pm 15.8 \mathrm{vs}+1.4 \pm 15.7, \mathrm{p}=0.03)$, a significant increase in the number $(6.1 \pm 28.8$ vs $-0.4 \pm 26.9, \mathrm{p}=0.03)$ and duration (4.3 \pm 20.1 vs $-1.7 \pm 20.7, p<0.01$ ) of the home-exercises in the active group, and a greater IPAQ score in the active group at the end of follow-up (138.4 \pm 227 vs 95.6 $\pm 173, \mathrm{p}=0.02$ ).

Conclusions: This study highly suggests a short-term benefit of a nurse led program on the self-management and self-assessment for disease activity in a young axSpA population in particular with regard to the frequency and the duration of home exercises.

Acknowledgements: This study was conducted thanks to a grant from the French National Research Program (PHRC) thanks to an unrestricted grant from ABBVIE.

Disclosure of Interest: None declared

DOI: 10.1136/annrheumdis-2018-eular.4181

\section{THURSDAY, 14 JUNE 2018}

\section{Fires and firefighters: switching the immune system on and off}

\section{OP0165 \\ JOINT-SPECIFIC DIFFERENCES IN THE ACTIVATION OF THE JAK-STAT PATHWAY IN RHEUMATOID ARTHRITIS}

T. Masterson, K. Klein, E. Karouzakis, O. Distler, C. Ospelt, M. Frank Bertoncelj. Center of Experimental Rheumatology Zurich, University Hospital Zurich, Schlieren, Switzerland

Background: Synovial fibroblasts (SF) promote chronic joint inflammation and joint destruction in rheumatoid arthritis (RA). We have shown recently that SF from different joints exhibit profound differences in their transcriptomes, epigenomes and functions, which creates a unique microenvironment in each joint. This might influence the susceptibility of distinct joints to develop RA or lead to joint-specific differences in the disease severity or therapeutic response.

Objectives: To analyse differences in the JAK-STAT pathway in SF from different joints.

Methods: SF were isolated from knee, shoulder and hand joints of RA and osteoarthritis patients undergoing joint replacement surgery and from knee synovia biopsies of non-arthritic subjects with arthralgia. Transcriptomes and epigenomes of SF were determined by RNA-seq, Illumina HiSeq $2000 n=21$ ), ChIP-seq (Illumina HiSeq 2500, $n=7)$ and Infinium HumanMethylation450 BeadChip $(n=12)$. We used MetaCore (Thomson Reuters) for the pathway enrichment analysis of RNA-seq data. SF were stimulated with IL-6/soluble IL-6 receptor (IL-6/sIL-6R, $50 \mathrm{ng} / \mathrm{ml}$ each). The amount of STATs and phospho-STAT3 (p-STAT3) was measured by Western blot with normalisation to $\alpha$-tubulin.

Results: The JAK-STAT pathway was enriched in knee SF versus hand and shoulder SF (FDR<0.05). JAK1 (normalised reads - mean \pm SD: 10673 \pm 2084 ) and STAT1 (15520 \pm 2678$)$ were the top expressed Janus kinase and STAT mRNAs in SF, respectively, whereas the expression of JAK3 $(40 \pm 26)$ and STAT4

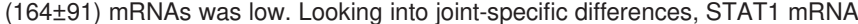
was higher in knee SF and shoulder SF compared with hand $S F(p<0.05$, FDR $<0.15$ ). Accordingly, STAT1 protein was increased in knee SF (STAT1/ $\alpha$ tubulin ratio: $0.83 \pm 0.02, p=0.02, n=4)$ and shoulder $S F(1.02 \pm 0.02, p=0.001, n=5)$ versus hand SF $(0.57 \pm 0.02, \mathrm{n}=3)$. JAK1, STAT2 and STAT5B mRNAs were higher in knee compared with hand SF $(\mathrm{p}<0.05$, FDR $<0.05)$ and STAT2 and STAT6 mRNAs were higher in knee versus shoulder $S F(p<0.05, F D R<0.05)$ TYK2 mRNA was high in hand SF compared with shoulder and knee SF $(p<0.05$, FDR<0.05). SF from different joints exhibited comparable DNA methylation at the promoters of these genes. Activating histone marks H3K4me3 and/or H3K27ac were enriched at the promoters of JAK1, STAT1, STAT2 and STAT5B in knee versus hand SF. This indicated that the abundance of activating histone marks at gene promoters might shape joint-specific expression of a subset of Janus kinase and STAT genes. Stimulation of SF with IL-6/sIL-6R increased the phosphorylation of STAT3 in knee (p-STAT3/ $\alpha$-tubulin ratio $1.8 \pm 1.0, p=0.03, n=5$ ) and shoulder SF $(1.8 \pm 0.7, p=0.03, n=6)$ compared with hand SF $(0.9 \pm 0.5, n=6)$. The basal amount of STAT3 protein and the ratio pSTAT3/STAT3 was higher in knee SF (STAT3/ $\alpha$-tubulin ratio: $0.8 \pm 0.1 ; p$-STAT3/STAT3: $2.2 \pm 0.8, n=3$ ) and shoulder SF $(0.6 \pm 0.4 ; 2.1 \pm 1, n=4)$ versus hand SF $(0.3 \pm 0.02 ; 1.0 \pm 0.4, n=2)$.

Conclusions: Here we show substantial quantitative and qualitative differences in the JAK-STAT signalling pathway in SF from different joints. Knee SF, in particular, exhibit increased expression of Janus kinase and STAT genes and enhanced JAK-STAT signalling upon stimulation with IL-6/sIL-6R. This suggests that RA in different joints might not be equally sensitive to Janus kinase inhibitors or blockade of IL-6. This has important implications in clinical practice and drug discovery in RA.

Disclosure of Interest: T. Masterson: None declared, K. Klein: None declared E. Karouzakis Grant/research support from: BTCure, GSK, O. Distler Grant/ research support from: Abbvie, Actelion, Bayer, Biogenldec, Boehringer Ingelheim, ChemomAb, espeRare foundation, Genentech/Roche, GSK, Inventiva iQone, Lilly, medac, Medlmmune, Mepha, MSD, Mitsubishi Tanabe Pharma, Novartis, Pfizer, Pharmacyclics, Sanofi, Sinoxa and UCB, Consultant for: Abbvie Actelion, Bayer, Biogenldec, Boehringer Ingelheim, ChemomAb, espeRare foundation, Genentech/Roche, GSK, Inventiva, iQone, Lilly, medac, Medlmmune Mepha, MSD, Mitsubishi Tanabe Pharma, Novartis, Pfizer, Pharmacyclics, Sanofi, Sinoxa and UCB, C. Ospelt Grant/research support from: euroTEAM BTCure, CABMM, IRR, Promedica, M. Frank Bertoncelj Grant/research support from: AbbVie Rheumatology grant 2017 euroTEAM, BTCure, IRR, Promedica, Georg und Berta Schwyzer Winiker Grant

DOI: 10.1136/annrheumdis-2018-eular.6708

\section{OP0166 COMPARATIVE EVALUATION OF CELLULAR AND MOLECULAR CHANGES ASSOCIATED WITH RESPONSE TO SELECTIVE IL-23 BLOCKADE VS DUAL IL-12/23 BLOCKADE IN PSORIASIS SKIN}

K. Li ${ }^{1}$, K. Campbell ${ }^{1}$, S. Garcet ${ }^{2}$, C. Brodmerkel ${ }^{1}$, J. Krueger ${ }^{2} .{ }^{1}$ Janssen Research and Development, LLC, Spring House; ${ }^{2}$ Laboratory for Investigative Dermatology, The Rockefeller University, New York, USA

Background: Emerging clinical data indicate that selective blockade of interleukin 23 (IL-23) can achieve greater efficacy compared to dual blockade of IL-12/23 in patients with moderate-to-severe psoriasis (PsO). ${ }^{1}$ Ustekinumab (UST) targets the p40 subunit common to IL-12 and IL-23, whereas guselkumab (GUS) specifically targets the IL-23-specific $\mathrm{p} 19$ subunit. While differences in antibody potency may explain therapeutic differences between UST and GUS, we explored cellula and molecular changes in the skin of PsO patients treated with UST or GUS to understand the mechanism underlying selective IL-23p19 inhibition. 